\title{
An integrated technique using solar and evaporation ponds for effective brine disposal management
}

\begin{abstract}
Desalination is a process that involves the removal of salts and non-ionic minerals from seawater to produce freshwater that is fit for human consumption. This process produces brine, which is typically redisposed into the sea. The relatively high salt concentration in the disposed brine increases the salinity of water and soil, which adversely affects the environment. However, brine is found to be rich in economically valuable minerals. In order to effectively manage the disposed brine, this study proposes an integrated technique using solar and evaporation ponds to filter valuable minerals from concentrated brine. The results of this study demonstrate that the proposed technique can be effectively employed for this purpose. Furthermore, this helps reduce desalination costs and complies with the notion of renewable energy production and eco-friendliness.
\end{abstract}

Keyword: Desalination; Rejected brine; Statistics; Solar pond; Evaporation pond; Fabrication 